\title{
Development of face shields by rapid prototyping: a socio-sanitary approach in defense of health professionals against Covid-19 in São Paulo, Brazil
}

\author{
Del Monaco ADM§, Aidar MEAS§, Augusto EAGS§, Biasi LBP§, Camargo RCS§, Coelho \\ GSC§, Leite FPL§, Losacco SCL§, Machado EMP§, Monteiro MSM§, Rodrigues YBRES§, \\ Santineli CSS§, Silva EAS§ \\ $\S$ University Center of Americas, São Paulo, Brazil.
}

\begin{abstract}
Humanity is being affected by the SARS-CoV-2 beta-coronavirus since December 2019. This disease has caused a high mortality rate due to easy contagion in pandemic mundial scale. The transmission occurs from human to human, through respiratory droplets and contact with aerosol-infected surfaces. Anyone carrying the virus that is close (i.e. less than 1 meter) to another person's eyes, nose or mouth, makes him/her susceptible because of direct contact with the contaminated particles he/she will have (e.g. by touching an infected surface and then touching the eyes, nose or mouth). Due to the risk of exposure to infection, given the forms of contamination by this virus and considering measures to control and protect against infections by health professionals, the Academic Rehabilitation League (LAR), formed by professors and students of the University Center of Americas, produced 400 facial protectors using 3D printing through models composed of polymer filaments, in addition to the acetate films visor and elastics for better fixation, these can be reused and sterilized easily. The masks were distributed free of charge to health professionals in the state of São Paulo, with the purpose of offering greater support, so that they can perform their work safely.
\end{abstract}

Keywords. 3D Printing, Personal protective equipment, SARS-CoV-2 Coronavirus, COVID-19, Face Shields.

Introduction. At the end of December 2019, in the city of Wuhan, Hubei Province, China, was detected a new coronavirus linked to a wet seafood market. Currently, the etiological agent has been named Coronavirus 2 of severe acute respiratory syndrome (SARS-CoV-2). The symptoms of COVID-19 disease, named by the World Health Organization (WHO) on February 11, 2020, appear after an incubation period and the cases of premature death from the COVID-19 outbreak occurred mainly in the elderly, possibly due to a weak immune system that allows a faster progression of viral infection. On March 11, 2020, the WHO declared a global pandemic and ordered people to stay at home to minimize the transmission of Coronavirus 2. On the other hand, 
health professionals from the country's public and private networks, as well as research institutions and controlled testing laboratories were prepared to do the exact opposite, remaining at the forefront of the fight against the disease. ${ }^{1,2}$

According to the WHO, the transmission of the virus occurs from an infected person to another by contact, such as coughing, nasal secretions, sneezing or saliva. Thus, the coronavirus can be transmitted by droplets suspended in the air. The use of masks represents a physical barrier, minimizing the risk of dissemination. However, the use does not replace the individual mask (surgical masks or PFF2 - N95) serving only as a complement, on masks and glasses. ${ }^{2}$

As the pandemic fosters, access to personal protective equipment (PPE) such as face shields masks has become extremely important to reduce contamination of individuals who are working on the front lines in fight against COVID-19. ${ }^{3}$ According to William Lindsley's project on the effectiveness of face shields against aerosol droplets, the facial shield mask can reduce immediate viral exposure by $96 \%$ with a simulation less than $50 \mathrm{~cm}$ from the cough. At a recommended distance of 2 meters, face shields masks have reduced viral exposure by $92 \%$. After 30 minutes, the protective effect exceeded $80 \%$ and the masks prevented aerosol drops by $68 \%$.4,5,6

In many developing countries, health system infrastructure has found it difficult to support the demand for efforts and equipment required by this pandemic. This has led to alarming emergencies and poor control of health and safety of the network. Knowing this relevance, the goal of Academic Rehabilitation League (LAR), formed by professors and students of the University Center of Americas, São Paulo is to develop a project, using additive manufacturing to make face shields masks by digitally produced models and subsequently sent to donations to help health professionals.

\section{Materials and methods}

Additive manufacturing techniques. For the rapid prototyping process, also popularly known as 3D printing, a computational file model is required, a widely used extension is .stl. For the present project, the .stl model developed by researchers from the Czech Republic was used as a basis, which shared it through a non-commercial license by PRUSAPRINTERS, 2020. This model featured prominences for fitting the acetate sheet, which should be punctured with a paper punch. In this way, these fitting prominences have been removed from the model and it has been adapted for an internal fitting system and easier assembly for the acetate sheet. As shown in Figure 1. 


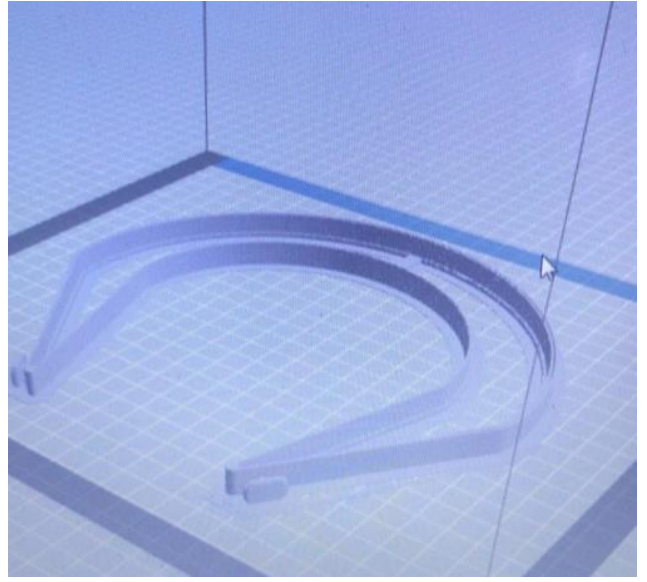

Figure 1: Face shield computer 3D arc model adapted for this project.

After adapting the 3D design, the drawing was sliced using the Ultimaker Cura software ${ }$, the model was printed by Tronxy X5SA 3D printer, with the following parameters suitable for prototyping with PLA: Layer hight $0.3 \mathrm{~mm}$; Infill density 50\%; Infill pattern octet; Printing temperature $200^{\circ} \mathrm{C}$; Build plate temperature $50^{\circ} \mathrm{C}$; Filament diameter $1.75 \mathrm{~mm}$; Print speed $60 \mathrm{~mm} / \mathrm{s}$; Travel speed $120 \mathrm{~mm} / \mathrm{s}$; No support generate; Build plate adhesion type brim with $4 \mathrm{~mm}$; Final print time 3h40min for 2 mask supports for procedure. Figure 2 shows the final face shield model assembly.

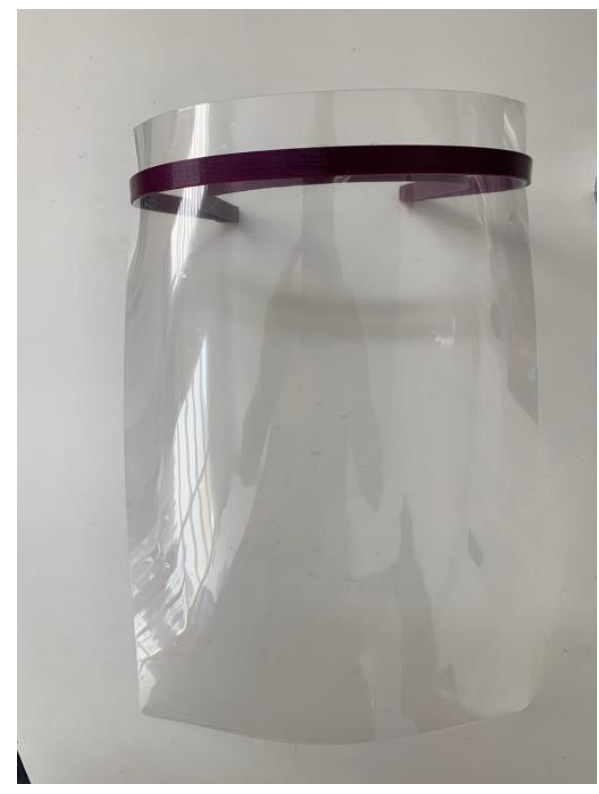

Figure 2: Final Face Shield model assembly. 
Assembly process. Once the additive manufacturing technique was put into practice, the assembly process of the face shields was carried out in a fast and practical way. With the printed arc model made of biopolymer polylactic acid (PLA) in hand, the acetate film was placed in the coupling gap and then, the elastic fixed on side pins for better stability during use.

After assembly, the masks were disinfected with $70 \%$ alcohol or polyhexamethylene biguanide (PHMB) and packed in cardboard boxes or plastic bags for transportation. Assembled, cleaned and properly packaged, the face shields were delivered to the professionals who work on the front line in the fight against COVID-19. Although the disinfection process was carried out after the assembly of the masks, it was recommended that they should be cleaned again before the first use. Figure 3 shows the flowchart for production.

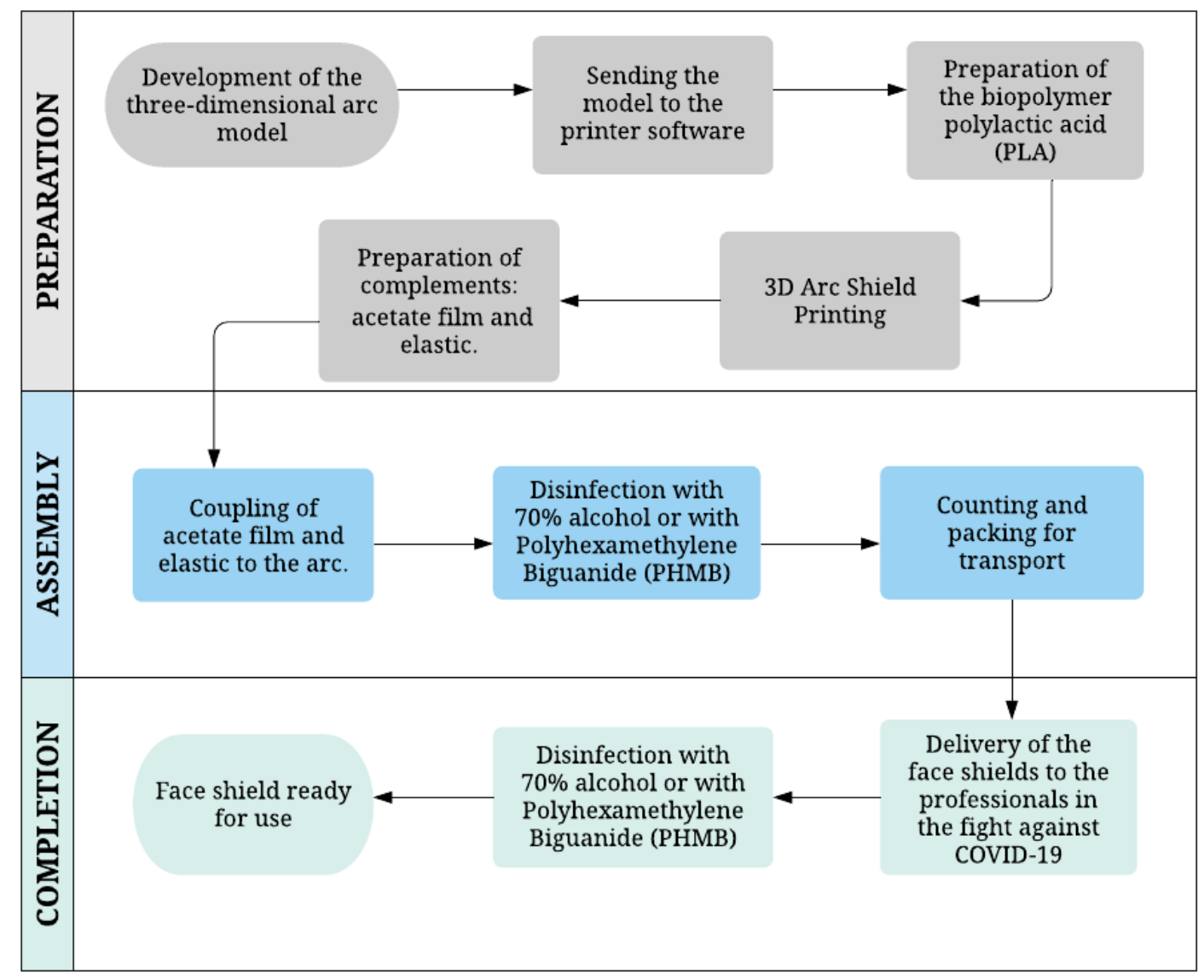

Figure 3: Production and assembly flowchart

Results and Discussion. The risk of infection for hospital staffs is higher than the rest of the population. Health professionals are a potential vehicle for the spread of SARS-CoV-2. With the 
spread of COVID-19 to the surplus population, more than 3300 healthcare workers were infected in China. In April 2020, Fursaroli, P. et al., reported the $100^{\text {th }}$ Italian physician infected with the disease. The vast majority of the first 100 victims among physicians occurred in Lombardia, the most affected region in general, followed by Emília-Romanha and Campânia.

The strategy to prevent the spread of the virus includes the use of appropriate personal protective equipment among health professionals, such as N95 masks, medical masks, eye protection, dressing gowns, gloves and facial protectors. ${ }^{8}$ However, the sudden arrival of the pandemic has caused a depletion of these materials at all three levels of government, federal, state and municipal, as well as in private networks. The São Paulo State Medical Association conducted a survey to map the opinions and working conditions of Brazilian physicians, especially from São Paulo city, in the midst of the new coronavirus pandemic (COVID-19). The survey was conducted in midApril and had the participation of 2312 professionals. The result was that $50 \%$ of the surveyed physicians reported the lack of N95 or PFF2 masks, suitable for blocking the coronavirus; $38.5 \%$ reported the lack of facial protection; $26 \%$ reported the lack of glasses; $31 \%$, of aprons; $36.5 \%$, of surgical masks. This demonstrates the importance of carrying out projects that promote the manufacture and donation of personal protective equipment. ${ }^{9}$

The 3D printing technology has reformulated biomedical engineering to design and develop new equipment as a flexible and powerful technique in the advanced manufacturing industry. Facial protectors come in many shapes, but all must provide a transparent plastic barrier that covers the face. For optimal protection, the shield should extend below the chin anteriorly, to the ears laterally, and there should be no exposed space between the forehead and the shield helmet. These simple features allow the design to be easily reproduced and effective. ${ }^{10,11}$ The application of the rapid prototyping technique by $3 \mathrm{D}$ printing in our project has proved to be an effective process in the production of the acetate sheet supports for the face shields. One disadvantage of this process is the manufacturing time of each piece. In other techniques like injection and cutting, for example, it would be possible to produce 10 times more, at the same time, but these equipment have a higher cost than a $3 \mathrm{D}$ printer.

Research has shown that the virus can survive for a different period, depending on the surface. Therefore, the WHO recommends ensuring that disinfection and environmental cleaning procedures are performed correctly and consistently. ${ }^{12,13}$ Over the years, disinfectants have been used in the hospital industry, in clinics, outpatients and offices, acting as infection prevention. ${ }^{10}$ These chemical agents promote the destruction of microorganisms in the vegetative form, in hospital articles or on surfaces. ${ }^{11}$ According to the National Health Surveillance Agency (ANVISA), after the use of IPEs, cleaning must be performed and then disinfected with $70 \%$ liquid 
alcohol, sodium hypochlorite or other disinfectant in the concentration recommended by the manufacturer. ${ }^{14}$

Face shields can be treated by the following processes: 1) Sodium hypochlorite (bactericide, fungicide, microbactericide and virucide, depending on the concentration), has fast action and leaves no residues, it can be used on surfaces and respiratory therapy materials. In the concentration of $0.1 \%$ it is effective for the disinfection of thermosensitive materials, such as masks, mechanical ventilator accessories and anesthesia devices, humidifiers, among others. The disinfection process with sodium hypochlorite is done by immersion of 15 to 30 minutes. 2) Ethyl alcohol 70\% - proceeds quickly on vegetative bacteria, viruses and fungi, but is not sporicide. It is recommended only for surface disinfection and skin antisepsis. ${ }^{11}$ 3) Polyhexamethylene Biguanide (PHMB) - Detergent and disinfectant. It has quick drying. It manifests a wide antimicrobial spectrum. It is used for cleaning and disinfecting hospital surfaces and equipment, such as infusion pumps, monitors, fans, glycemia devices, among others. ${ }^{12}$

The sterilization processes of the materials used in the making of the masks must allow the inactivation of a wide variety of microorganisms, including toxic and resistant bacterial spores without altering the characteristics of the material. This type of process differs from disinfection in that it can destroy virtually all forms of micro-organisms and is divided into chemical and physical processes. According to Del Monaco (2018), the methods that can be used for the sterilization of face shields are: hydrogen peroxide plasma, ethylene oxide and ultraviolet (UV) radiation. They are effective in destroying microorganisms and the chemical denaturing of proteins, but do not use high temperatures for this. ${ }^{15}$

Safety cameras equipped with UV-C type ultraviolet lamps are used for sterilization. The ultraviolet radiation only has a microbicidal effect when used with sufficient intensity and exposure time, its wavelengths below 200nm are inefficient for this application, because the radiations in the range of 210 and 330nm can be considered efficient as germicides, because they are absorbed by proteins and nucleic acids, causing chromosomal disruption, genetic mutations and inactivation of enzymes that lead to cell death. In general, ultraviolet radiation has proven to be a faster, more reliable, effective, economical, and environmentally safe way to sterilize face shields. ${ }^{15}$

In hydrogen peroxide plasma sterilization, STERRAD® Plasma Hydrogen Sterilization (Sterrad Sistem ${ }^{\circledR}$ - Johnson \& Johnson ${ }^{\circledR}$ ) uses a combination of plasma and hydrogen peroxide vapor $\left(\mathrm{H}_{2} \mathrm{O}_{2}\right)$ at low temperature and without toxic residues. Hydrogen peroxide is a bactericide, tuberculiscide, sporicide and fungicide and acts through the production of free radicals that damage lipid membranes, DNA and other essential cellular components. The STERRAD® sterilization 
cycle consists of hydrogen peroxide vapor injection into the treatment chamber and emission of microwaves that generate plasma with free radicals that have the ability to denature proteins, leading to cell death. Unlike the UV method, plasma can reach regions of devices with more complex geometries. ${ }^{15}$

For this project, so far 400 face shields have been produced and donated to healthcare professionals. The project will be extended until the end of the pandemic in Brazil.

Conclusion. The pandemic caused by COVID-19 is one of the major problems facing the world health system today. This virus has arrived quickly, bringing to light the deficiency in the infrastructure of the global health system. Specially in development countries, these problems are mainly caused by the lack of personal protective equipment, putting the employees of hospitals, health posts and COVID-19 service centers at imminent risk of contamination. For a professional who acts in the front line to fight the disease, a higher level of protection is required, and due to this reality the use of PFF2 - N95 masks overlapping face shields is crucial to reduce the spread of the disease among professionals who put their own lives at risk to save others. Even with the success of the 400 face shields masks donations to various professionals carried out by the LAR, there are still many unprotected employees nationally and internationally. Some months have passed since the beginning of this pandemic, and the health system still has difficulty in meeting the current needs of its employees, therefore, increasing investment and better management is necessary in order to protect health workers and then minimize contamination and the deaths caused by this pandemic.

\section{References}

(1) Hussin A., Siddappa N. USA. Journal of Autoimmunity: The epidemiology and pathogenesis of coronavirus disease (COVID-19) outbreak. 2020.

(2) Lisa C., William R., David W., Mark S. Coronavirus Survival on Healthcare Personal Protective Equipment, 2010.

(3) Willian G. L., John D. N., Francoise M. B., Jonathan V. S., Donald H. B. Online: Efficacy of Face Shields Against Cough Aerosol Droplets from a Cough Simulator. 2014.

(4) Saule L. P. J., Superintendent of Urgency and Emergency. Florianopolis (SC): NOTA INFORMATIVA nº 001/2020 - SAMU / DAPM / SUE / SES. 2020 Apr 7, c2020- [cited 2020 May 25]. Available from: http://www.saude.sc.gov.br/coronavirus/arquivos/nota_informativa_001_2020_PROTETOR_FA CIAL.pdf. Published in partnership with Superintendência de Urgência e Emergência (SUE), 
TAS Journal, vol. 4, n. 2, p. 123- 130.

ISSN 2595-1521

JUNE 2020

adri.delmonaco@gmail.com

Diretoria de Atendimento Pré-Hospitalar Móvel (DAPM) and Serviço de Atendimento Móvel de Urgência (SAMU).

(5) World Health Organization; c2020-. Covid-19: Sobre a doença; [cited 2020 May 25]. Available from: https://coronavirus.saude.gov.br/sobre-a-doenca.

(6) ANVISA [serial on the Internet]. Brasilia (FD): ORIENTAÇÕES GERAIS - Máscaras faciais de uso não profissional. 2020 Apr 3, c2020- [cited 2020 May 25]. Available from: http://portal.anvisa.gov.br/documents/219201/4340788/NT+M\%C3\%A1scaras.pdf/bf4301848550-42cb-a975-1d5e1c5a10f7.

(7) Pietro F., Sara B., Andrea L. Italy: Springer Verlag GmbH. On the death of 100+Italian doctors from COVID-19, 2020.

(8) N. Shahrubudin, T.C. Lee, R. Ramlan. 2nd International Conference on Sustainable Materials Processing and Manufacturing (SMPM 2019): An Overview on 3D Printing Technology: Technological, Materials, and Applications. 2019.

(9) Associação Paulista de Medicina (APM) [serial on the internet]. São Paulo (BR): Os médicos e a pandemia do novo coronavírus (COVID-19). 2020 Apr [cited 2020 June 1]. Available from: http://associacaopaulistamedicina.org.br/files/2020/pesquisa-apm-medicos-covid-19abr2020.pdf.

(10) The Journal of Hospital Infection [serial on the internet]. Germany: Persistence of coronaviruses on inanimate surfaces and their inactivation with biocidal agents. $2020 \mathrm{Feb} 6$ [cited 2020 June 1]. Available from: https://www.journalofhospitalinfection.com/article/S01956701(20)30046-3/fulltext. Published in partnership with Healthcare Infection Society and Elsevier.

(11) Hadis F., Parham M., Mansooreh M., Sounkalo D., Şükran K., Khudaverdi G., Pasquale P., Silvano E., Hossein S. Protection and Disinfection Policies Against SARS-CoV-2 (COVID-19), 2020.

(12) Sociedade Beneficente Israelita Brasileira [homepage on the Internet]. Brazil: Albert Einstein; Manual Farmacêutico: Antissépticos [revised 2018 Apr 12; cited 2020 May 27].

Available from:

https://aplicacoes.einstein.br/manualfarmaceutico/Paginas/Termos.aspx?filtro=antiss\%C3\%A9pt icos\&itemID=26\#detalheTermo.

(13) Lenita W. Brasilia (FD): Anti-sépticos desinfetantes e esterilizantes. c2010- [revised 2015 Sept 16; cited 2020 May 27].

(14) ANVISA [serial on the Internet]. Brasilia (FD): NOTA TÉCNICA GVIMS / GGTES / ANVISA No. 04/2020. 2020 Jan 30 [revised 2020 May 8; cited 2020 May 27]. Available from: http://portal.anvisa.gov.br/documents/33852/271858/Nota+T\%C3\%A9cnica+n+042020+GVIMS-GGTES-ANVISA/ab598660-3de4-4f14-8e6f-b9341c196b28.

(15) Del Monaco ADM, Duek ER, Andrade AJP, Malmonge SM. Alternative methods of sterilization on films of polymers: Poly(-L-lactic acid) (PLLA), Poly(L-lactic acid-co-glycolic acid) (PLGA) and Poly(-LD-lactic acid) (PLDLA), for bioresorbable vascular scaffolds models. TAS Journal, vol. 2, n. 4, p. 248-256: 2018. 